\title{
Integrated development of carrying capacities of the Baikal-Amur Mainline and Trans-Siberian Railway
}

\author{
Andrey Borodin ${ }^{1, *}$, Petr Kozlov ${ }^{2}$, and Anatoly Kalinichenko ${ }^{3}$ \\ ${ }^{1}$ Institute of Transport Economics and Development JSC, 105066 Moscow, Russia \\ ${ }^{2}$ Transportny Algorithm LLC, 109029 Moscow, Russia \\ ${ }^{2}$ INTEGRAL Company LLC, 121099 Moscow, Russia
}

\begin{abstract}
The paper considers actual technical and technological problems in the development of the Eastern polygon of the Russian railway network. The purpose of the study is to develop a methodology and software tools that ensure the search for effective solutions for given resource and logistical constraints. Methods of simulation modeling, distribution of flows on networks and graphs are used. The result of the study is a hybrid set of model calculations.
\end{abstract}

\section{Introduction}

The integrated investment project "Modernization of the Railway Infrastructure of the Baikal-Amur Mainline and Trans-Siberian Railway with the Development of Throughput and Carrying Capacities" is among high-priority projects aimed at developing the Russian transport system. Its implementation since 2013 has already provided major results in logistics support of the national economy and its export potential [1]. Volumes of goods shipped from the major mineral deposits on the Eastern polygon are expected to increase from 58.1 million tonnes in 2012 to 124.9 million tonnes in 2020 and to 184.7 million tonnes in 2024.

The scale and complexity of the problems to be solved by the project require a significant scientific and methodological support, new algorithms and software for calculating effective parameters, as well as a database for decision-making. The key methodological problems include:

1. limited investment resources and possibilities to construct and reconstruct the railway infrastructure to the extent and within the time frames as required under the integrated project.

2. The boundaries of the polygon within which investment activities are carried out do not coincide with the boundaries in which technological, commercial, socioeconomic and budgetary effects and losses should be calculated.

3. Integrated investment projects for railway infrastructure development contain target indicators, such as traffic capacity of railway sections; carrying capacity of railway sections

\footnotetext{
* Corresponding author: borodinaf@mail.ru
} 
in freight transportation directions; standard and average weights of freight trains; sectional speed of freight trains; route speed of passenger trains.

The applicable regulations set forth requirements for parameters of channels in the transport system (as defined in [2]), but do not contain any requirements for parameters of bunkers. Parameters of channels (as defined in the railway terminology) include traffic capacities of stations, sections and junction tracks, handling capacities of classification yards and cargo terminals. Bunkers are characterized by capacities of tracks used for accumulating trains and regulating their departures.

The paper [3] shows the consequences of underestimated properties and parameters of bunkers in the development of a railway network. In case of excess car fleet, part of yard tracks is excluded from traffic and handling operations with trains and cars. At the same time, the resulting traffic capacity of the railway infrastructure is significantly reduced relative to rated values calculated in accordance with the applicable instruction [4]. In order to take these factors into account, methodological provisions of studies [5-9] should be further developed. The existing flow control models are aimed at building some optimal dynamic processes. They include a dynamic transportation problem for managing empty car flows in dynamics [10]; a dynamic matching method for designing coordinated delivery of goods to ports [11]; a software package ELBRUS for generating an optimal multivariate train schedule according to a specified criterion [12].

It is only imitation models that can verify the effectiveness of these methods at specific polygons and in close-to-real conditions. The novelty of the study is in solving the methodological problems listed above. The purpose of the study is to develop a methodology, algorithms and software tools that ensure the search for effective solutions for given resource and time constraints in delivery of goods and empty cars.

\section{Research methods}

Bottlenecks of the railway infrastructure are classified in the applicable regulations. The concept of "bottleneck" is used in the General Railway Network Development Scheme [5, 6] and in supporting materials of investment projects: it is defined as a railway section whose traffic capacity is utilized above the allowable level set by the applicable instruction [4]. As shown in [1], the length of these bottlenecks will be increasing (as compared to $2013)$ and reach over $8,000 \mathrm{~km}$ (75\% of the total length of the Baikal-Amur Mainline and Trans-Siberian Railway) in 2020 and about 10,000 km (more than $90 \%$ of their total length) in 2025.

At the same time, it has been proved [2] that the greatest delays in transport flows do not always arise from the most loaded infrastructure element. Therefore, it is proposed to distinguish between (Fig. 1):

a bottleneck of the first kind (an element loaded above the allowable level according to [4]);

a bottleneck of the second kind (an element that causes delays in acceptance of trains by railway stations or neighboring railway units);

a bottleneck of the third kind (a process operation that causes the greatest or unacceptable delays). 


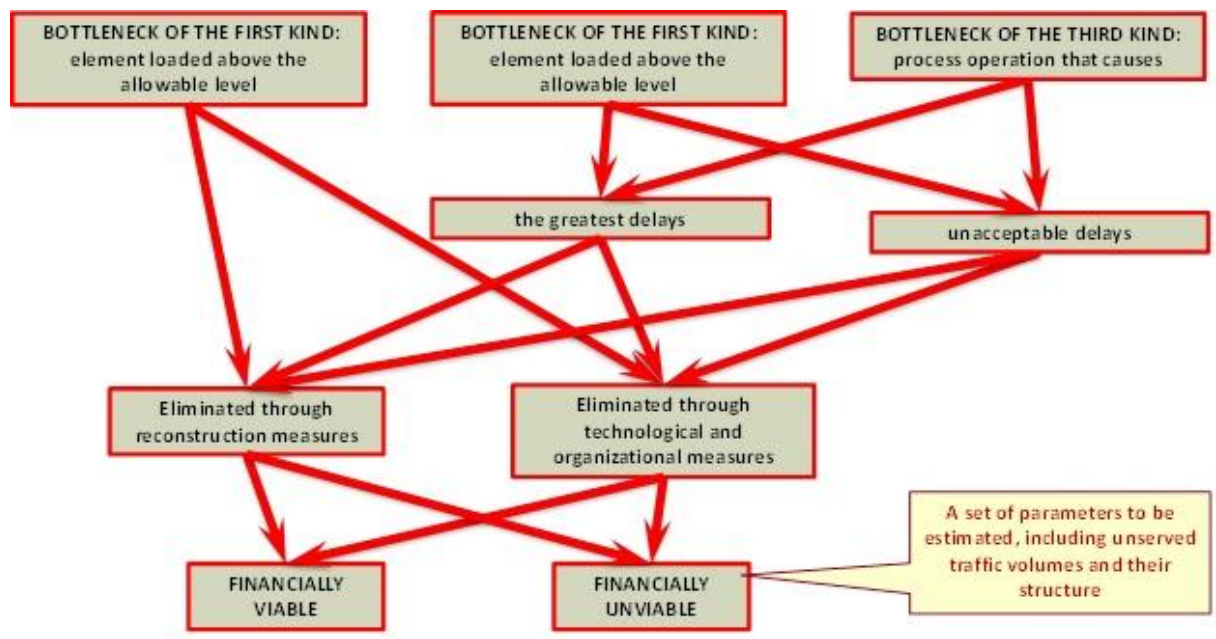

Fig. 1. Classification of bottlenecks and methods to remove them.

Removal of all bottlenecks only through reconstruction may lead to excessive need for investments and higher costs of subsequent operation. This solution is unacceptable.

Therefore, a methodical approach to solving a problem development and operation of the railway infrastructure and transportation resources in an integrated way was formulated and applied. The components of the solution contain controlled variables of three categories: (1) investment in infrastructure development; (2) adjustment of the number and structure of locomotive and car fleets; (3) improvement of a traffic management technique to minimize non-productive use of rolling stock and infrastructure capacities.

The solution must meet the following requirements. Sets of reconstruction measures should be sufficiently invariable to fluctuations of traffic flows (cargo base, passenger flows, car fleet management system). Infrastructure should allow railway carriers to regulate car traffic in the current operating conditions by redistributing car flows among its elements. This regulation involves using parallel railway routes, redistribution of classification operations among railway stations and yards, etc.

The following categories of process solutions aimed at maximizing the utilization of available traffic capacities of bottleneck sections were tested for the polygon of the BaikalAmur Mainline and Trans-Siberian Railway.

1. To reduce standard processing time of trains in receiving-departure yards of technical stations.

2. To install parallel inputs and outputs (three-track insert rails) on the sections adjacent to technical stations.

3. To accelerate turnover of innovative high-capacity cars for reducing the total required volume of freight traffic.

4. To increase loaded train traffic passing through sections of the Baikal-Amur Mainline under an unpaired traffic schedule by returning empty car traffic through the sections of the Trans-Siberian Railway in trains of 100 conditional cars.

\section{Results}

The result of the study is a set of hybrid mathematical models developed and applied to solve the problems described above. Statistical analysis and forecasting components of this set are designed to calculate dynamics and structure of traffic flows. Network flow models 
allow traffic flows to be distributed. Simulation models can be used to calculate performance indicators.

Based on the results of the study, a simulation modeling technique was prepared and then approved by Russian Railways in 2018. It contains clear requirements for simulation systems and resulting models of stations and polygons. Automated simulation systems ISTRA (for stations) and IMETRA (for polygons) best meet these requirements. The models based on these systems can be used to assess the effectiveness of measures aimed at developing transport infrastructure and technological improvements.

Outputs of the model simulation are real traffic and handling capacities of a simulated object, utilization rate of individual devices, and related delays. Models provide additional information to designers and technologists. This information includes, for example, representation of processes in dynamics. A mimic diagram representing the station model demonstrates train and shunting movements, location of locomotives and track loading (Fig. 2).

On a mimic diagram representing the polygon model, traffic of trains on sections and their location at stations are marked with arrows (Fig. 3). As clearly seen from the presented fragment, station 3 is obviously overloaded. When switching to a graph of completed traffic, one can see how this overloading causes significant waiting times (Fig. 4).

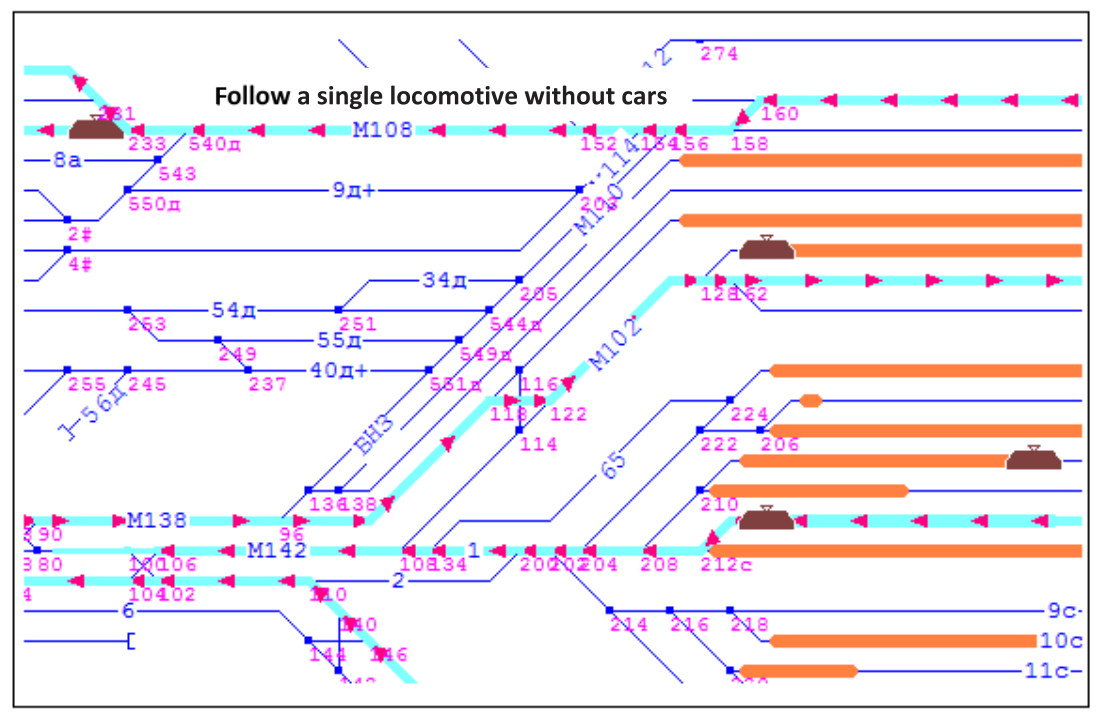

Fig. 2. Dynamics of processes in the station model. 


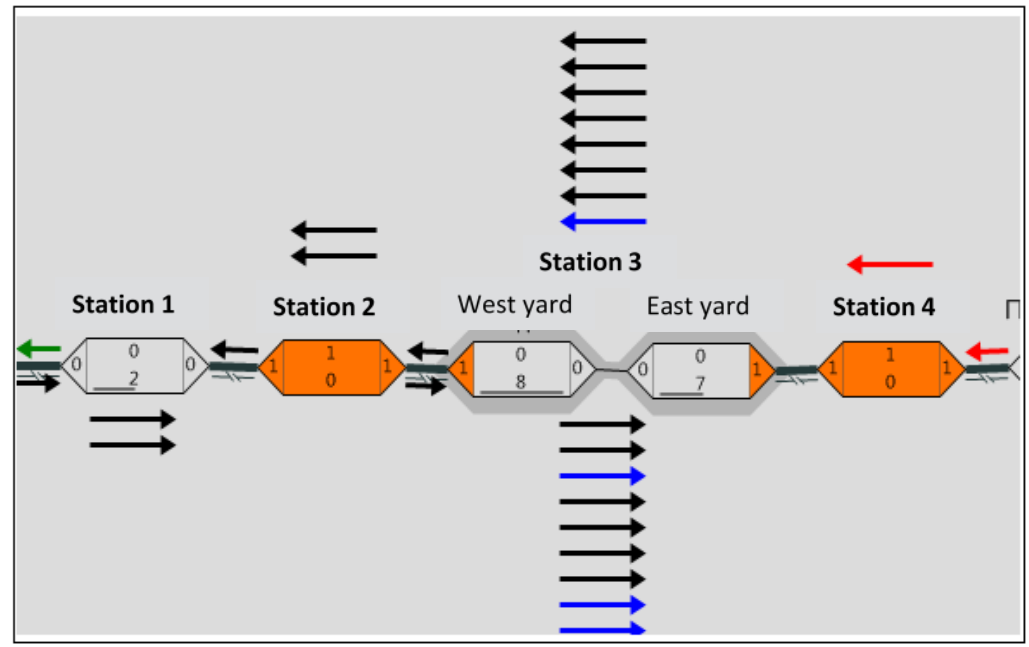

Fig. 3. Dynamics of processes in the polygon model.

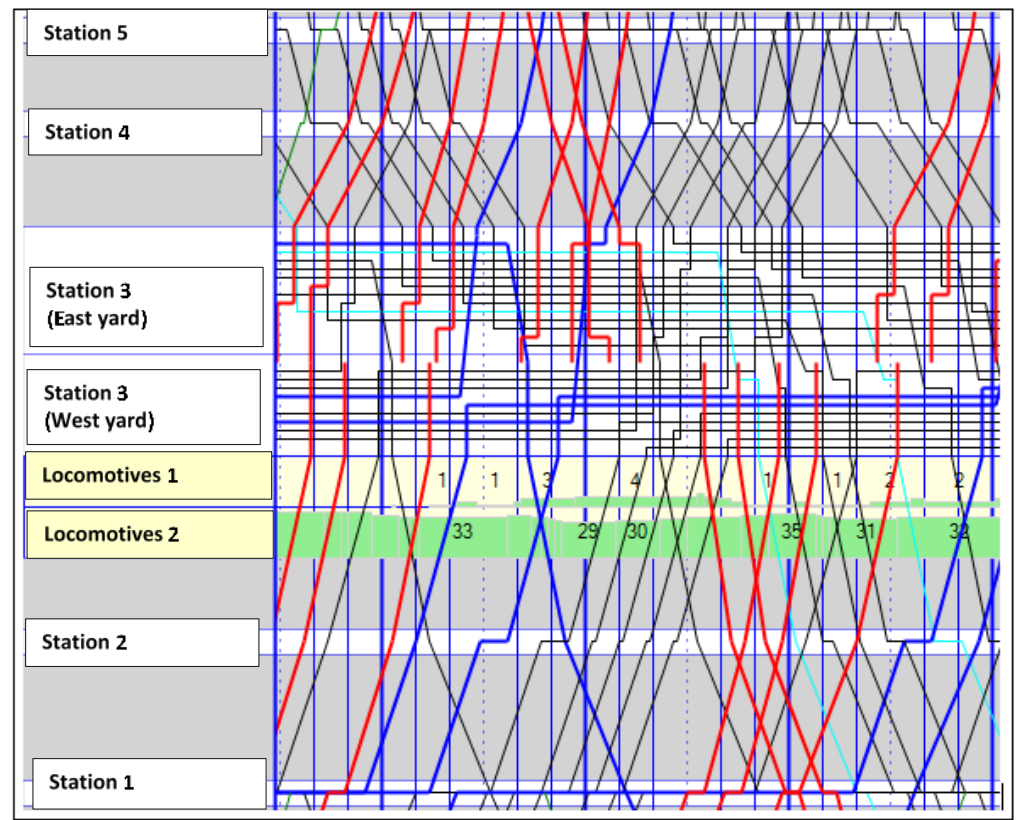

Fig. 4. A fragment of graph representing completed traffic in the polygon model.

\section{Conclusion}

The supporting materials for the integrated project "Modernization of the Railway Infrastructure of the Baikal-Amur Mainline and Trans-Siberian Railway with the Development of Throughput and Carrying Capacities" were elaborated in detail using the presented methodological solutions and software tools. The results contain multivariate calculations and an integrated selection of parameters for managing passenger and freight flows. The proposed traffic management technique includes traffic interchanges, a junction 
technology with non-public tracks, choice of routes for car traffic, standard weight and length of trains, traffic routing, a train making-up plan, traction facilities, and a train schedule. As a result, target indicators of the projects were calculated. The progress towards their achievement was synchronized with specific investment measures.

The traffic management technique is being considered jointly with Russian Railways, a technology auditor of the project, and Consumer Council for Working with Russian Railways. Coordinated issues are being submitted to the Committee for Russian Railways Priority Investment Projects of the Government of the Russian Federation. Thus, the practical calculations and preliminary approval of the results by experts confirm that the developed methods are applicable and effective in justifying parameters of upgrading the railway infrastructure, in particular the Eastern polygon of the Russian railway network.

\section{References}

1. A.F. Borodin, M.V. Storchak, Bjulleten' Obyedinennogo uchenogo soveta OAO RZD [Bulletin of the Joint Scientific Council of Russian Railways JSC], 2, 65 - 73 (2017). (in Russian)

2. P.A. Kozlov, Mir transporta [World of Transport and Transportation Journal], 12, 2(51), 30 - 37 (2014). (in Russian).

3. E.A. Sotnikov, Ekspluatacionnaja rabota zheleznyh dorog (sostojanie, problemy, perspektivy) [Operational work of railways (condition, problems, prospects)] (Transport, Moscow, 1986). (in Russian)

4. Russian Railways JSC, Instrukcija po raschetu nalichnoj propusknoj sposobnosti zheleznyh dorog [Instructions for calculating the available capacity of railways] (Techinform, Moscow, 2011). (in Russian)

5. F.S. Pekhterev, Zheleznodorozhnyj transport [Railway transport], 5, 4 - 9 (2012). (in Russian)

6. F.S. Pekhterev, Bjulleten' Obyedinennogo uchenogo soveta OAO RZD [Bulletin of the Joint Scientific Council of Russian Railways JSC], 13 - 22 (2015). (in Russian)

7. A.A. Assad, Transportation Research Part B: Methodological, 14, Issues 1-2, 101-114 (1980).

8. X. Wang, Q. Meng, Transportation Research. Part B: Methodological, 95, 76-104 (2017).

9. A. Petraska, A. Jarasuniene, K. Ciziuniene, Procedia Engineering, 178, 589-596 (2017).

10. I.P. Vladimirskaya, Doctoral thesis, Moscow State University of Railway Engineering, Moscow, 2011. (in Russian)

11. P.A. Novikov, Transport of the Urals, 2 (17), $72-75$ (2008). (in Russian)

12. L.A. Muginshteyn, A.Yu. Anfinogenov, V.Yu. Kiryakin, S.A. Vinogradov, O.V. Lyashko, L.N. Ponarin, Imitacionnoe modelirovanie $v$ zadachah organizacii dvizhenija poezdov [Simulation modeling in the tasks of organizing train traffic] (Intekst, Moscow, 2012). (in Russian) 